\title{
Synthesis and utilization of epoxidized polybutadiene rubber as an alternate compatibilizer in green-tire composites
}

\author{
Vivek K. Srivastava $^{1}$ - Ganesh C. Basak ${ }^{1} \cdot$ Madhuchhanda Maiti $^{1}$. \\ Raksh Vir Jasra ${ }^{1}$
}

Received: 31 August 2016/Accepted: 24 August 2017/Published online: 6 September 2017

(c) The Author(s) 2017. This article is an open access publication

\begin{abstract}
In the present study, epoxidized polybutadiene rubber (EBR) was synthesized from commercial-grade cispolybutadiene rubber (BR) and was characterized by NMR, FTIR, differential scanning calorimetry, thermogravimetric analysis and surface energy by contact angle measurement. To circumvent the drawback of the existing compatibilizers, the EBR was successfully used as an alternate compatibilizer for a silica-based 'green-tire' composite. The significant rise of surface energy was observed after epoxidation of $\mathrm{BR}$, which represents the enhancement of the polar character of the rubber chains and eventually leads to improved compatibility between silica fillers and rubber chains. Out of various epoxidation levels, EBR with $30 \mathrm{~mol} \%$ epoxidation showed the best compatibilizing effect. The optimum loading of EBR was found to be $12 \%$ with respect to total silica content. Apart from using EBR alone as a compatibilizer, combination of EBR with commercial silane-coupling agents, namely, bis(triethoxy-silylpropyl) tetrasulphide (TESPT) and 3-aminopropyltrimethoxy silane, was also investigated. The physico-mechanical and dynamic properties of the compounds with a combination of TESPT:EBR (40:60-60:40) were comparable with those of the compound prepared using TESPT compatibilizer. The results observed with EBR-compatibilized samples revealed that EBR has a potential to be an effective compatibilizer which eventually could minimize the drawbacks associated while using commercial silane as a compatibilizer at the industrial scale.
\end{abstract}

Vivek K. Srivastava

vivek.k.srivastava@ril.com

1 Vadodara Manufacturing Division, Reliance Research and Development Center, Reliance Industries Ltd., Vadodara, Gujarat 391346, India
Keywords Epoxidized polybutadiene rubber . Compatibilizer · Surface energy · Physico-mechanical properties

\section{Introduction}

The development of 'green tires' with lower rolling resistance along with safety and fuel efficiency is the focus of the current tire research and developments. In fact, the 'green-tire' concept was introduced in early 90s and has emerged as a paradigm shift towards the improvements of tire's wet grip (safety) and rolling resistance (fuel efficiency) simultaneously [1-3]. Moreover, the impulsion and the advantages associated with 'green-tire' concept initiated the investigation and utilization of various types of novel fillers like nanosilica, nanoclay etc., to replace or to avoid the conventional carbon black [4, 5]. However, as compared to the carbon black, the use of other fillers such as nanosilica in the rubber composites encounters few major challenges such as [6-9];

- poor rubber-filler interaction due to difference of polar characteristics and

- filler agglomeration due to higher filler-filler interaction.

As a result of above-mentioned limitations, the rubber composites prepared using nanofillers lead to poor processability, inferior mechanical strength and unacceptable dynamic properties. However, such challenges can be resolved up to greater extent using compatibilizers or coupling agents which reduces the difference in polar characters of fillers and rubbers and leads to improved rubber-filler interactions $[10,11]$. Typically, on industrial scale, the modification of silica surface is done by 
introduction of coupling agents or compatibilizers like silanes, which reduce the filler-filler interaction and also enhance the rubber-filler interaction through chemical linkages between the silica surface and rubber chains $[12,13]$. However, from industrial production viewpoint, the use of silanes as compatibilizer has shown the following major disadvantages:

- the coupling reaction produces alcohols as by-products which may cause chronic defects in the final product [14];

- the higher material costs of the coupling agents; and

- the higher production costs due to the difficult processing behavior.

On the other hand, in the absence of silanes, the compatibility between fillers and rubbers can be enhanced by increasing the polar characteristics in the rubber chains which ultimately reduces the risks associated with their utilizations [15]. In the case of polyolefins, in general, functionalization such as epoxidation, carboxylation, oxidation, sulfonation, maleination etc., are known [16-18].

However, among the various functionalizations, the epoxidation of unsaturated $-\mathrm{C}=\mathrm{C}-$ bond at mild reaction condition is a wonderful synthetic tool for introduction of versatile functionality to the rubber chain. The epoxidation of rubber chain is an excellent synthetic tool to increase the polar character by introduction of oxirane/epoxy ring to the rubber chain. The epoxidation of the rubber and polymer chains can be carried out by both methods: solution and melt-mixing $[19,20]$. The epoxidation is carried out to serve dual purpose, to improve the functionality, and also to enhance the polar character of the non-polar rubber and polymer chains. Moreover, a controlled epoxidized rubber would possess both the polar group epoxy ring and nonpolar hydrocarbon chain to interact with polar silica surface and a non-polar rubber chain, respectively. Advantageously, the epoxidized BR can also be co-cured with the main rubber matrix smoothly.

The silica and silane-based styrene-butadiene rubber/ polybutadiene rubber (SBR/BR) composites are currently being used in passenger car radial tire-tread [21]. In the present study, the commercial-grade high cis-polybutadiene rubber (BR) was epoxidized to synthesize epoxy-BR (EBR) at different epoxidation magnitude, and thus, prepared EBRs were used to replace and/or reduce the coupling agent from SBR/BR composites. Although the use of epoxidized polydienes has been reported as compatibilizer for silica filler in a few patents [22-25], however, a comprehensive study has not been reported on the effect of epoxidation levels on compatibilization in the open literature [26]. Therefore, the present study focuses on the following major aspects:
- epoxidation of tire-grade high $c i s$-polybutadiene rubber $(5,10,30$, and $50 \mathrm{~mol} \%$ epoxidation) to prepare the epoxidized polybutadiene rubber (EBR);

- evaluation of compatibilizing efficacy of thus synthesized EBR in silica-filled SBR/BR blend at various epoxidation levels and loadings;

- comparative study of EBR as a compatibilizer with commercially used silanes like bis(triethoxy-silylpropyl) tetrasulphide (TESPT) and 3-amino propyl trimethoxy silane (APS).

\section{Experimental}

\section{Materials and methods}

BR (Cisamer 01, $\mathrm{ML}_{1+4} @ 100{ }^{\circ} \mathrm{C}=45 ; M_{\mathrm{w}}=3.5 \times 10^{5}$, cis content $96 \%$ ) was obtained from Reliance Industries Ltd., India. SBR (1502, Mooney viscosity $\mathrm{ML}_{1+4} @$ $100{ }^{\circ} \mathrm{C}=48$ ) was obtained from Japan Synthetic Rubber, Japan. Sulfur, stearic acid (98\% purity), zinc oxide ( $\mathrm{ZnO})$, $\mathrm{N}$-Cyclohexyl-2-benzothiazole sulphenamide (CBS) $(98 \%$ purity), diphenyl guanidine (DPG), microcrystalline wax, precipitated silica, and bis(triethoxy-silylpropyl) tetrasulphide (TESPT) were purchased from Labort Fine Chem. Pvt. Ltd., India. $N$-(1, 3-dimethyl butyl)- $N$-phenyl-pphenylenediamine (6PPD) was obtained from John Baker Inc., USA. 3-amino propyl trimethoxy silane (APS) was procured from Sigma-Aldrich Inc., USA. Naphthenic oil and di-tertiary-butyl-para cresol (DTBPC) were obtained from indigenous sources. meta-Chloroperbenzoic acid (MCPBA, 70\%) was procured from Sigma-Aldrich, India.

\section{Synthesis of epoxidized polybutadiene rubber (EBR)}

A variety of different magnitude of epoxidation $(5,10,30$, and $50 \mathrm{~mol} \%$ ) of BR were conducted using modified protocol (Scheme 1) [27].

Typically for $10 \mathrm{~mol} \%$ epoxidation, in a three-neck round-bottom flask equipped with magnetic stirrer, $16.2 \mathrm{~g}$ of BR $(0.3 \mathrm{~mol}$ of $\mathrm{C}=\mathrm{C})$ was first dissolved in $1000 \mathrm{ml}$ of toluene. A solution of $7.38 \mathrm{~g}$ of MCPBA $(0.03 \mathrm{~mol})$ in $300 \mathrm{ml}$ of toluene was subsequently added drop-wise at room temperature into the rubber solution at such a rate that the MCPBA solution was added in $1 \mathrm{~h}$. The reaction mixture was then further stirred for another $3 \mathrm{~h}$. After $3 \mathrm{~h}$, the stirring was stopped and epoxidized rubber was obtained by precipitation in methanol containing $0.5 \%$ DTBPC as an antioxidant. The rubber was decanted and then washed twice with methanol before subjecting to vacuum drying at room temperature for $5 \mathrm{~h}$. The 10, 30, 
Scheme 1 Epoxidation reaction of polybutadiene rubber

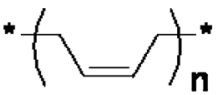

BR and $50 \mathrm{~mol} \%$ epoxidized polybutadiene rubbers were designated as EBR10, EBR30 and EBR50 respectively.

\section{Preparation of rubber composites}

A variety of rubber composites were prepared by meltmixing method. Mixing was carried out in a Brabender Plasticorder (PL2000, Germany), an internal mixer (volume $50 \mathrm{~cm}^{3}$ ) adopting a three-stage mixing procedure at $60 \mathrm{rpm}$. Mixing temperature of first, second, and third stages was 120,140 and $80{ }^{\circ} \mathrm{C}$ (unless otherwise mentioned). Different composites were prepared according to the formulations given in Table 1. The final curing of compound was done on compression molding at $145{ }^{\circ} \mathrm{C}$ and $10 \mathrm{MPa}$ pressure at optimum cure time.

\section{Testing methods of different composites}

Dumbbell-shaped samples were cut from the molded sheets according to ASTM D412-96 for tensile strength and ASTM D624 for tear strength. The tensile strength, elongation at break, modulus and tear strength were determined on a Universal Testing Machine (Instron 3367, USA) with the crosshead speed of $500 \mathrm{~mm} / \mathrm{min}$. Hardness was measured using $6 \mathrm{~mm}$-thick sample in Durometer (Wallace,

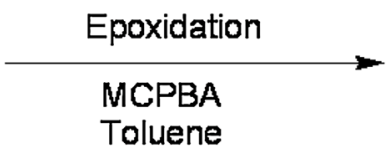

RT

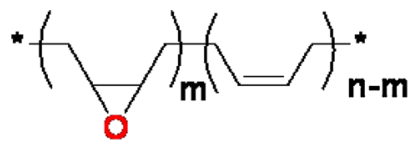

E-BR
UK) according to ASTM D2240-97. For determining the abrasion resistance of the composites, cylindrical test pieces were molded. The tests were performed according to DIN 5316 in DIN Abrader (Zwick Roell, Germany). Cut and chip test was performed on Cut and Chip Tester (Alpha Technologies, USA). The conditions of testing were: sample speed $750 \mathrm{rpm}$, cut and chip cycle $60 \mathrm{rpm}$ and cycle time $10 \mathrm{~min}$. Circular sample of $50 \mathrm{~mm}$ diameter was used. Dynamic mechanical thermal analysis was done using DMA VA4000 (Metravib, France) in double sandwich shear mode. Strain sweep experiments were done in the range of $0.1-40 \%$ strain at $60{ }^{\circ} \mathrm{C}$. Sample dimension was of $10 \mathrm{~mm}$ in diameter and $2.0 \pm 0.2 \mathrm{~mm}$ of thickness.

The volume fraction of rubber in the swollen network, $V_{\mathrm{r}}$, was calculated by equilibrium swelling method and crosslink density was subsequently calculated by the wellknown Flory-Renner equation [28]. Rheology studies were carried out using Hybrid Rheometer from -120 to $100{ }^{\circ} \mathrm{C}$ at $10 \mathrm{~Hz}$ frequency and $0.1 \%$ strain [29]. The bound rubber content was determined as per method proposed by the reported literature [30]. The surface energy of the solid polymers was determined by contact angle measurement. Fowkes [31] proposed that the surface energy of a pure phase is a sum of the contribution from the dispersive $\gamma_{a}^{\mathrm{d}}$ and polar $\gamma_{\mathrm{a}}^{\mathrm{p}}$ components, such that

Table 1 Formulation and designation of rubber composites

\begin{tabular}{|c|c|c|c|c|c|c|c|c|c|c|c|c|c|}
\hline \multirow{2}{*}{$\begin{array}{l}\text { Ingredients } \\
\text { Sample name }\end{array}$} & \multicolumn{13}{|c|}{ Formulation in $\mathrm{phr}^{\mathrm{a}}$} \\
\hline & A & B & $\mathrm{C}$ & $\mathrm{D}$ & $\mathrm{E}$ & $\mathrm{F}$ & G & $\mathrm{H}$ & I & $\mathrm{J}$ & $\mathrm{K}$ & $\mathrm{L}$ & M \\
\hline SBR & 70 & 70 & 70 & 70 & 70 & 70 & 70 & 70 & 70 & 70 & 70 & 70 & 70 \\
\hline $\mathrm{BR}$ & 30 & 30 & 30 & 30 & 30 & 30 & 30 & 30 & 30 & 30 & 30 & 30 & 30 \\
\hline EBR (mol\%) & - & - & - & $8.4(10)$ & $8.4(30)$ & $8.4(50)$ & $5.6(30)$ & $17.5(30)$ & $35(30)$ & $4.2(30)$ & $3.4(30)$ & $5.0(30)$ & $5.0(30)$ \\
\hline Precipitated silica & 70 & 70 & 70 & 70 & 70 & 70 & 70 & 70 & 70 & 70 & 70 & 70 & 70 \\
\hline TESPT & - & 8.4 & - & - & - & - & - & - & - & 4.2 & 5.0 & 3.4 & - \\
\hline APS & - & - & 8.4 & - & - & - & - & - & - & - & - & - & 3.4 \\
\hline Zinc oxide & 5 & 5 & 5 & 5 & 5 & 5 & 5 & 5 & 5 & 5 & 5 & 5 & 5 \\
\hline Stearic acid & 2 & 2 & 2 & 2 & 2 & 2 & 2 & 2 & 2 & 2 & 2 & 2 & 2 \\
\hline 6PPD & 2 & 2 & 2 & 2 & 2 & 2 & 2 & 2 & 2 & 2 & 2 & 2 & 2 \\
\hline Wax & 1 & 1 & 1 & 1 & 1 & 1 & 1 & 1 & 1 & 1 & 1 & 1 & 1 \\
\hline Naphthenic oil & 8 & 8 & 8 & 8 & 8 & 8 & 8 & 8 & 8 & 8 & 8 & 8 & 8 \\
\hline Sulfur & 1.3 & 1.3 & 1.3 & 1.3 & 1.3 & 1.3 & 1.3 & 1.3 & 1.3 & 1.3 & 1.3 & 1.3 & 1.3 \\
\hline CBS & 1.3 & 1.3 & 1.3 & 1.3 & 1.3 & 1.3 & 1.3 & 1.3 & 1.3 & 1.3 & 1.3 & 1.3 & 1.3 \\
\hline DPG & 1.5 & 1.5 & 1.5 & 1.5 & 1.5 & 1.5 & 1.5 & 1.5 & 1.5 & 1.5 & 1.5 & 1.5 & 1.5 \\
\hline
\end{tabular}

${ }^{\mathrm{a}}$ Parts per 100 parts of rubber 
$\gamma_{\mathrm{a}}=\gamma_{\mathrm{a}}^{\mathrm{d}}+\gamma_{\mathrm{a}}^{\mathrm{p}}$.

A contact angle meter, Kernco (Model G II) was adopted for contact angle measurement, using water and formamide as testing liquids. Contact angle of water and formamide on $\mathrm{BR}$ is $93.01^{\circ}$ and $74.52^{\circ}$, respectively. Contact angle of water and formamide on EBR is $79.76^{\circ}$ and $64.74^{\circ}$, respectively. Now

$\cos \theta=-1+\frac{2\left(\gamma_{\mathrm{s}}^{\mathrm{d}} \gamma_{1}^{\mathrm{d}}\right)^{1 / 2}}{\gamma_{1}}+\frac{2\left(\gamma_{\mathrm{s}}^{\mathrm{p}} \gamma_{1}^{\mathrm{p}}\right)^{1 / 2}}{\gamma_{1}}$

where $\gamma_{\mathrm{s}}^{\mathrm{d}}$ and $\gamma_{\mathrm{s}}^{\mathrm{p}}$ are the dispersive and polar components of solid's surface energy and $\gamma_{1}^{\mathrm{d}}, \gamma_{1}^{\mathrm{p}}$ are the dispersive and polar components of liquid's surface energy. Using Eqs. 1 and 2, the surface energy of BR and EBR was calculated.

\section{Results and discussion}

\section{Characterization of epoxidized polybutadiene rubber}

As mentioned earlier, introduction of oxirane group into the rubber chain was aimed to increase the polar character of the polybutadiene rubber chain. The extent of epoxidation was calculated by a methods as described in the literature, e.g., ${ }^{1} \mathrm{H}-\mathrm{NMR}$ (Bruker-400 MHz AVANCE-III, Germany) and FTIR (Nicolet 6700, USA) spectroscopy and addition of $\mathrm{HCl}$ in dioxane solution method $[19,20]$. The extent of epoxidation was quantified by NMR spectroscopy. A new singlet at $2.9 \mathrm{ppm}$ (-CH of epoxy) in EBR samples was observed in comparison to the NMR spectrum of BR (Fig. 1). The epoxidation of polybutadiene rubber was further confirmed by ATR-FTIR method. After epoxidation, in comparison to polybutadiene rubber, the appearance of new peaks at 809 and $1260 \mathrm{~cm}^{-1}$ (due to C-O-C- stretching of epoxy group) was observed (Fig. 2). It was also noticed that the peak height increases with the extent of epoxidation. The typical ${ }^{1} \mathrm{H}-\mathrm{NMR}$ resonance signals of BR and corresponding EBR30 samples are given below [19, 20, 27].

BR: ${ }^{1} \mathrm{H}$ NMR $\left(400.13 \mathrm{MHz}, \mathrm{CDCl}_{3}\right)$ : in ppm 0 . 911-1.444 (m, $\left.0.12 \mathrm{H},-\mathrm{CH}_{3}\right), 2.093\left(\mathrm{~s}, 2.04 \mathrm{H},-\mathrm{CH}_{2}\right)$, 5.026-5.395 (m, $1.02 \quad \mathrm{H},=\mathrm{CH})$. EBR: ${ }^{1} \mathrm{H} \quad \mathrm{NMR}$ (400.13 MHz, $\left.\mathrm{CDCl}_{3}\right)$ : in ppm 1.251-1.500 (m, $0.71 \mathrm{H},-$ $\left.\mathrm{CH}_{3}\right), 1.514-1.800\left(\mathrm{~m}, 0.24 \mathrm{H},-\mathrm{CH}_{3}\right), 1.951-2.291(\mathrm{~m}$, $\left.2.71 \mathrm{H},-\mathrm{CH}_{2}\right), 2.939-3.001(\mathrm{~m}, 0.24 \mathrm{H},-\mathrm{C}-\mathrm{O}-\mathrm{C}-\mathrm{Oxi}-$ rane), $5.101-5.640(\mathrm{~m}, 1.53 \mathrm{H},=\mathrm{CH})$.

The samples were also characterized and compared by thermal analysis such as DSC, TGA and DTG studies. The glass transition temperature $\left(T_{\mathrm{g}}\right)$ of a rubber changes expected to be increased on the introduction of oxirane ring. As shown in Fig. 3, similar kind of results was also observed in which the $T_{\mathrm{g}}$ was increased from $-103{ }^{\circ} \mathrm{C}$ (BR) to $-99{ }^{\circ} \mathrm{C}$ (EBR30). The change in $T_{\mathrm{g}}$ of the EBR is attributed to the fact that the presence of rigid polar bond in place of unsaturated group. Moreover, the single $T_{\mathrm{g}}$ value also implies the uniform distribution of epoxy group along with the BR main chain. The TGA and DTG studies have also been carried out to observe the effect of degradation pattern in the presence of oxirane ring into the $\mathrm{BR}$ chain (Fig. 4). A single pattern in the range of $300-480{ }^{\circ} \mathrm{C}$ in TGA curves and two distinct weight loss peaks in the DTG curves were observed. It is observed that the beginning of thermal degradation ( $\left.T_{\text {onset }}\right)$ marginally delays on the introduction of oxirane ring in the BR chain. On the other hand, the maximum degradation temperature $\left(T_{\max }\right)$ increases by $2^{\circ}$ from 448 to $450{ }^{\circ} \mathrm{C}$.

A change in the surface energy of the rubber chains represents variance in the polar characters. To quantify the extent of variance of polar character, the surface energy of one of the synthesized epoxidized BR was compared with corresponding virgin BR. The surface energy of BR and EBR5 was calculated to be 24.72 and $29.79 \mathrm{~mJ} / \mathrm{m}^{2}$, respectively. Hence, it was observed that typically, 5\% epoxidized BR has shown about $20 \%$ rise in the surface energy in comparison to the virgin BR. Such increment of surface energy clearly indicates that the polar character has been significantly increased after epoxidation of the BR. Finally, the ${ }^{1} \mathrm{H}-\mathrm{NMR}$, FTIR, DSC, TGA, and surface energy studies clearly signify that the presence of epoxy ring leads to increments of polar character in the BR chains.

\section{Effect of different magnitude of epoxidation level of EBR as a coupling agent}

The effect of different magnitude of epoxidation level of EBR on the mechanical properties of SBR/BR-silica composites is shown in Table 2. The lower mechanical properties were observed in the SBR/BR-silica composite without using compatibilizer (Sample A; Table 2) which may be due to higher filler-filler interaction and therefore, resulted poor dispersion of the silica filler in the rubber matrix. On the contrary, while using EBR10 and EBR30 as a compatibilizer, the tensile strength of the rubber composite was increased by 16 and 39\%, respectively (Sample D and Sample E; Table 2) in comparison to the rubber composite without using compatibilizer (Sample A; Table 2). However, lower values of the physico-mechanical properties were observed while using higher magnitude of epoxidized, EBR50 (Sample F; Table 2). This could be due to higher polarity at $50 \%$ epoxidation level, which makes epoxidized rubber incompatible with non-polar SBR/BR blends. Although EBR50 with higher level of epoxidation may react better with silica but due to 
Fig. $1{ }^{1} \mathrm{H}-\mathrm{NMR}$ spectra of BR and EBR30 samples
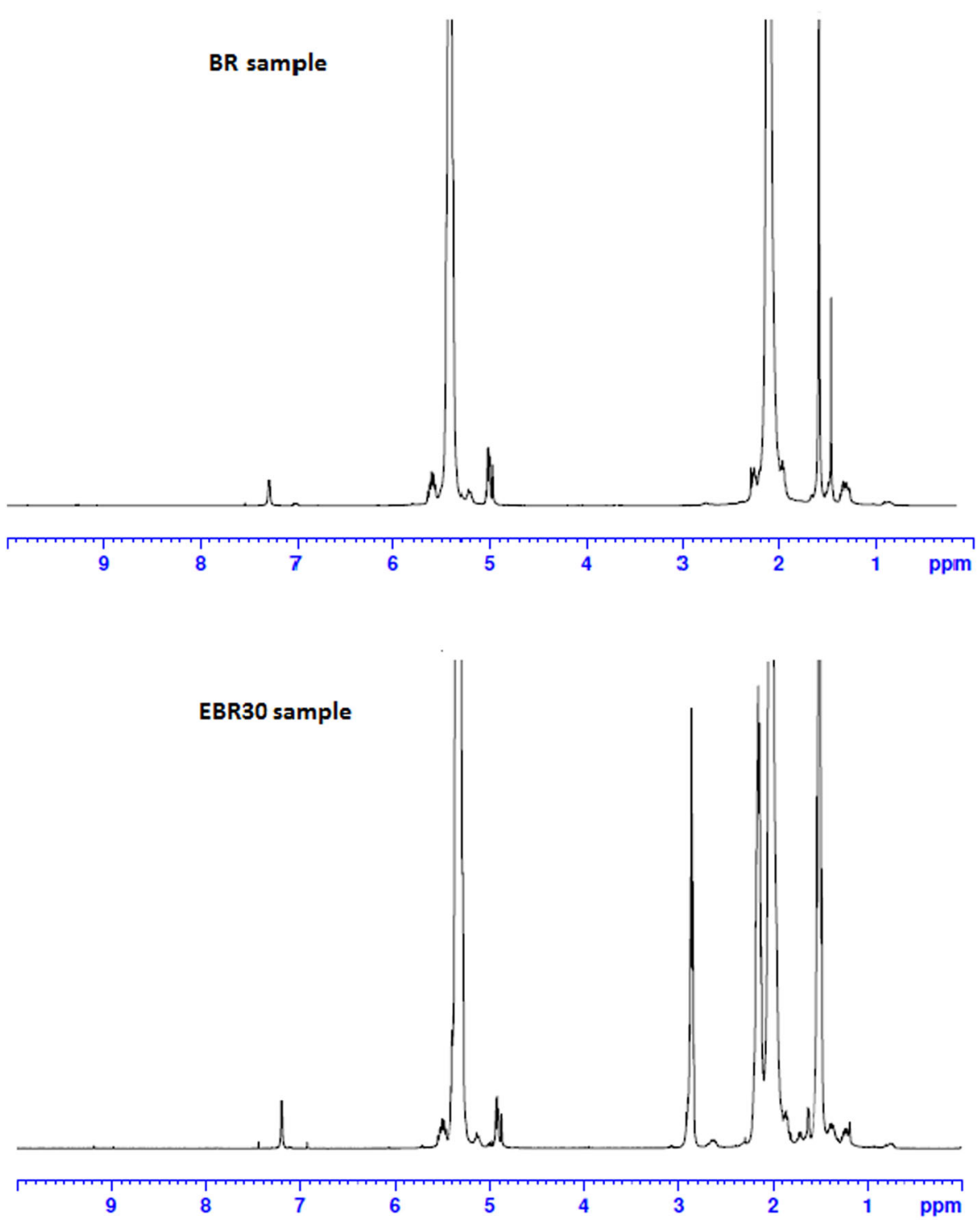

incompatibility with the SBR/BR blend matrix, the improved effect of compatibilization was not realized in the Sample F. Significantly higher improvement in the tensile strength was observed in the rubber composites sample containing the conventional silane-coupling agents, TESPT (95\% increment, Sample B and Sample A; Table 2) and APS $(51 \%$ increment, Sample C and Sample A; Table 2). Such improvements are due to better filler dispersion and filler-rubber interaction in the presence of conventional compatibilizers. The abrasion resistance and hardness values of the composites follow the trend: Sample B $>$ Sample A $>$ Sample E $>$ Sample $\quad$ D $=$ Sample F $>$ Sample C (Table 2). The abrasion resistance and cut and chip are both closely related wear properties of the rubber composites.

The volume fraction of rubber in the swollen network $\left(V_{\mathrm{r}}\right)$ for the studied rubber composites follows the trend:
Sample B $>$ Sample E $>$ Sample C $>$ Sample D $>$ Sample $\mathrm{A}>$ Sample $\mathrm{F}$ (Table 2). The highest value of $V_{\mathrm{r}}$ was observed for the composite samples containing TESPT as a compatibilizer because of the presence of sulfur molecule in the TESPT (Scheme 2), which facilitated the crosslinking density of the silica-silane-rubber network. On the other hand, better $V_{\mathrm{r}}$ values were also observed while using EBR30 as a compatibilizer in the SBR/BRsilica composite (Sample E; Table 2) which further confirms that the presence of polar epoxidized BR improves the crosslink density in the composite sample in comparison to sample A.

In general, it has been observed that the acidic silica surface tries to make a strong hydrogen bond with basic cure activators and consequently the crosslink density reduces in the vulcanized rubber samples. To improve the crosslink density of silica-filled rubber, the silane-coupling 

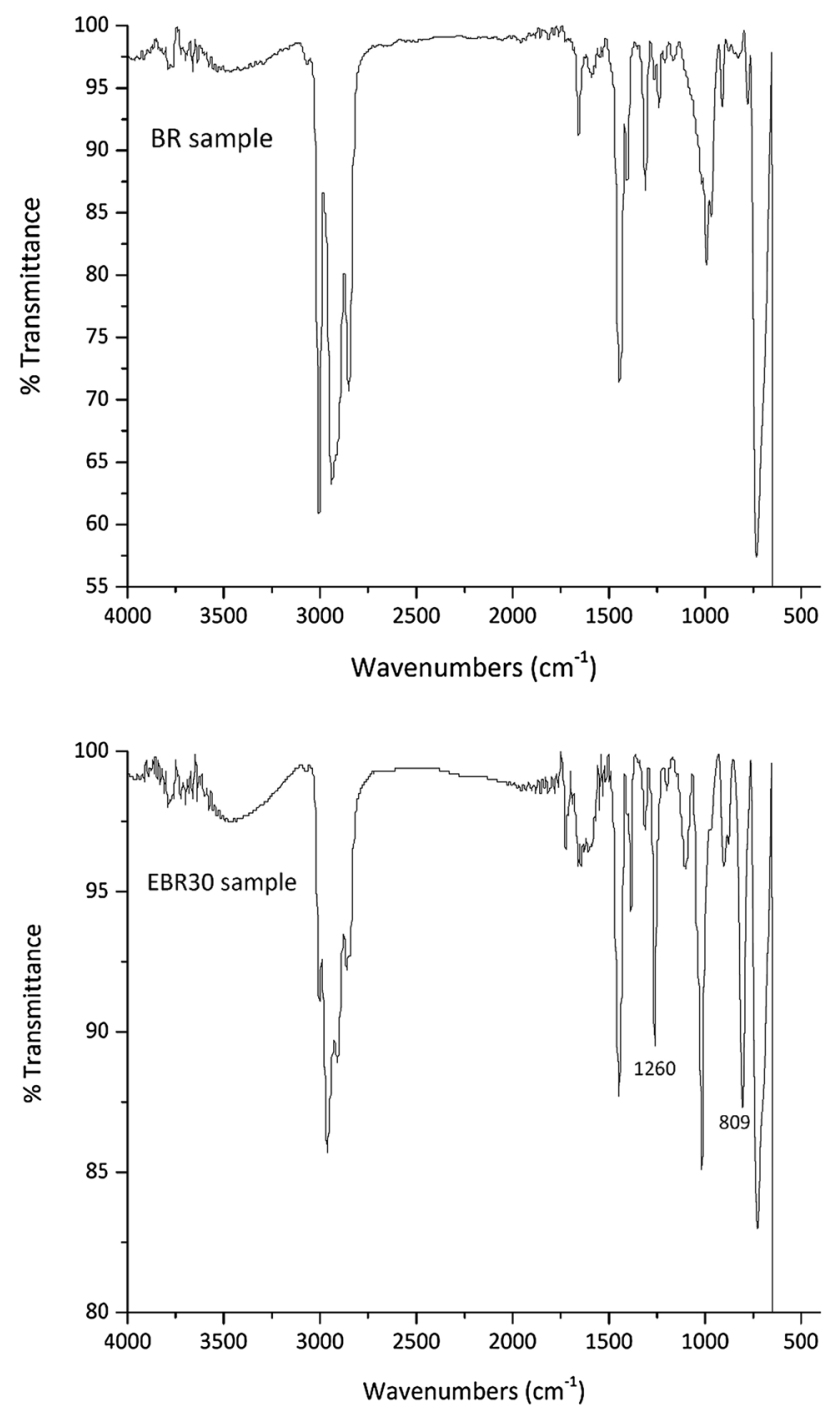

Fig. 2 FTIR spectra of BR and EBR30 samples

agents come into picture which basically prevents the adsorption of the curatives on the silica surfaces by modifying the silica surface and makes crosslinks between silica and rubber chain. The polarity of the polybutadiene rubber is increased in the presence of polar epoxy group. This enhances the strong interaction between rubber and silica in comparison to sample without silanes (Sample A). This might be the reason behind the improvement of crosslink density of Sample L in the presence of polar epoxidized BR.

Finally, it can be concluded that among the employed EBR samples, EBR30 showed a better improvement in the physico-mechanical properties while using as a compatibilizer in the SBR/BR-silica composites.

A proposed coupling reaction between silica surface and EBR is shown in Scheme 3. The surface silanol group of silica reacts with epoxy group of EBR, while the non-polar part of EBR is compatible with non-polar SBR/BR blend.
To support the proposed mechanism of Scheme 3, the FTIR spectra of EBR30 and the composites sample made from EBR30 and silica are compared (Fig. 5). It was observed that the peak at $810 \mathrm{~cm}^{-1}$ due to oxirane ring of EBR30 sample was disappeared in the composite sample of EBR30 and silica.

\section{Effect of variation of EBR concentration on compatibilization}

Out of the employed EBR samples, the EBR30 (30\% epoxidized BR) showed encouraging compatibilizer properties. Therefore, to investigate the optimum loading level, further studies were carried out by variation of loading of EBR30 as 8, 12, 25 and 50 weight \% of total silica content in the SBR/BR-silica composites. The highest tensile strength was observed at $12 \%$ loading (Fig. 6) as compared to higher (25 and 50\%) as well as lower (8\%) loading of EBR30. Other properties like modulus at 300\% elongation, hardness, and tear strength also followed the similar trend (Figs. 6, 7). It may be presumed that at lower loading, the amount of epoxy groups may not be sufficient to interact with the polar silica filler. On the other hand, at higher EBR, loading increases the polarity difference between polar-EBR and non-polar SBR/BR created incompatibility and leads to inferior compatibilization effect.

\section{Effect of EBR30 as partial substituent of silane}

Though during our investigations, EBR samples showed encouraging results as a potential compatibilizer for SBR/ BR-silica composites, however, the physico-mechanical properties were not observed better than the composites samples containing the conventional silanes, especially for TESPT. Similar observation was also reported earlier for other rubber composites samples [26]. Moreover, to observe the synergetic effects and also to minimize the disadvantages associated with the conventional silanes, another approach was undertaken by replacement of some part of conventional silanes by EBR samples SBR/BRsilica composites. A variety of SBR/BR-silica composites were prepared using different combination of TESPT and EBR30 samples. The ratio of TESPT:EBR30 was varied as 40:60 (Sample J), 50:50 (Sample K), and 60:40 (Sample L) and the results obtained are reported in Table 3.

As compared to the composite samples containing exclusively EBR as a compatibilizer (Sample E; Table 2), significant improvements (up to $31 \%$ ) were observed for the tensile strength of composite samples containing the combination of EBR30:TESPT as compatibilizer (Sample L; Table 3). However, the expected synergy was not observed using a combination of TESPT and EBR in the composites as the mechanical and the wear properties were 
Fig. 3 DSC curves of BR and EBR30 samples

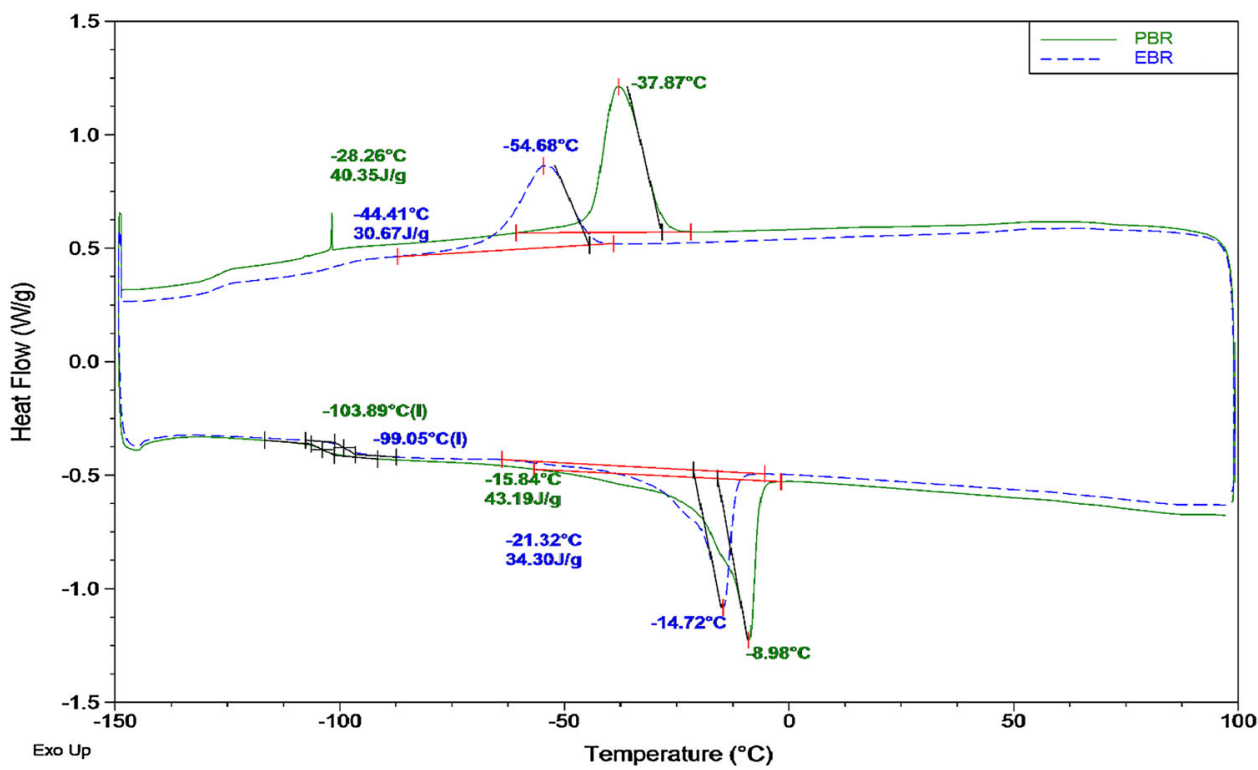

only comparable but not better than those of TESPT containing composite sample (Sample B; Tables 2, 3). Thus, it can be concluded that $40-60 \%$ of silanes can be substituted by EBR which can minimize the drawbacks associated while using only silane as a compatibilizer.

On the other hand, the Sample M (sample containing combination of EBR30:APS) showed mechanical properties inferior to both the composite sample containing alone APS (Sample C; Tables 2, 3) and EBR30 (Sample E; Table 2). The possible reason could be the non-availability of polar oxirane ring of EBR30 to function as compatibilizer because of the stoichiometric reaction between aminogroup of APS and oxirane ring of EBR30 as represented in Scheme 4. Eventually, the remaining oxirane ring of EBR30 was not adequate to provide a better compatibilization effect into the SBR/BR-silica composite.

\section{Rheology studies and bound rubber content}

The cure characteristics such as scorch time $\left(t_{2}\right)$, cure time $\left(t_{90}\right), M L$ and delta torque of various important samples are given in Table 4. It was observed that except Sample M, all the samples have shown a significant decrease of ML value which indicates reduction of filler-filler interactions within the rubber matrix. Moreover, it was also observed that sample containing only TESPT compatibilizer (Sample B) has shown the highest extent of ML reduction followed by the Sample $\mathrm{K}$ and Sample $\mathrm{L}$ in comparison to the Sample A (without any compatibilizer). In addition, improved crosslinking efficiency, which is reflected by highest values for both $\mathrm{M}_{\mathrm{H}}$ and delta torque for the sample containing only TESPT compatibilizer (Sample B) followed by Sample L and Sample K in comparison to Sample A (without any compatibilizer). Moreover, to investigate the rubber-filler interaction, the bound rubber content values were also determined (Table 5). It was observed again that sample containing only TESPT compatibilizer (Sample B) has shown the highest percentage of bound rubber values followed by the Sample L, Sample K, and Sample M in comparison to the Sample A (without any compatibilizer).

\section{Payne effect}

To investigate further filler-filler interactions, the Payne effect studies were carried out. The Payne effect was calculated by the difference between the elastic modulus at 0.18 degree strain and at 2 degree strain $\left[\Delta G^{\prime}=\left(G^{\prime} @ 0.18-G^{\prime} @ 2.0\right)\right]$ in uncured and cured samples at $1 \mathrm{~Hz}$ and $100{ }^{\circ} \mathrm{C}$ (Figs. 8, 9). For the uncured samples, as expected, it was observed that there is a maximum reduction in $\Delta G^{\prime}$ for Sample $\mathrm{B}$ due to the presence of TESPT coupling agent in the rubber matrix. Afterwards, the maximum reduction of $\Delta G^{\prime}$ was occurred for Sample L (Fig. 8). This might be a favorable interaction between epoxy groups and the hydroxy $(-\mathrm{OH})$ group onto the silica surface and, therefore, improve dispersion leading to reduction of Payne effect was observed. However, for the all cured samples, there is an increase in $\Delta G^{\prime}$ magnitude was observed (Fig. 9) owing to the probable reinteraction of the filler particles by the low viscosity during crosslinking formation at higher temperature.

\section{SEM microscopy studies}

To investigate the dispersion of silica filler particles in the rubber matrix, the SEM microscopy studies of various samples were carried out. As shown in Fig. 10, the silica 
Fig. 4 TGA and DTG thermogram patterns of $\mathrm{BR}$ and EBR30 samples
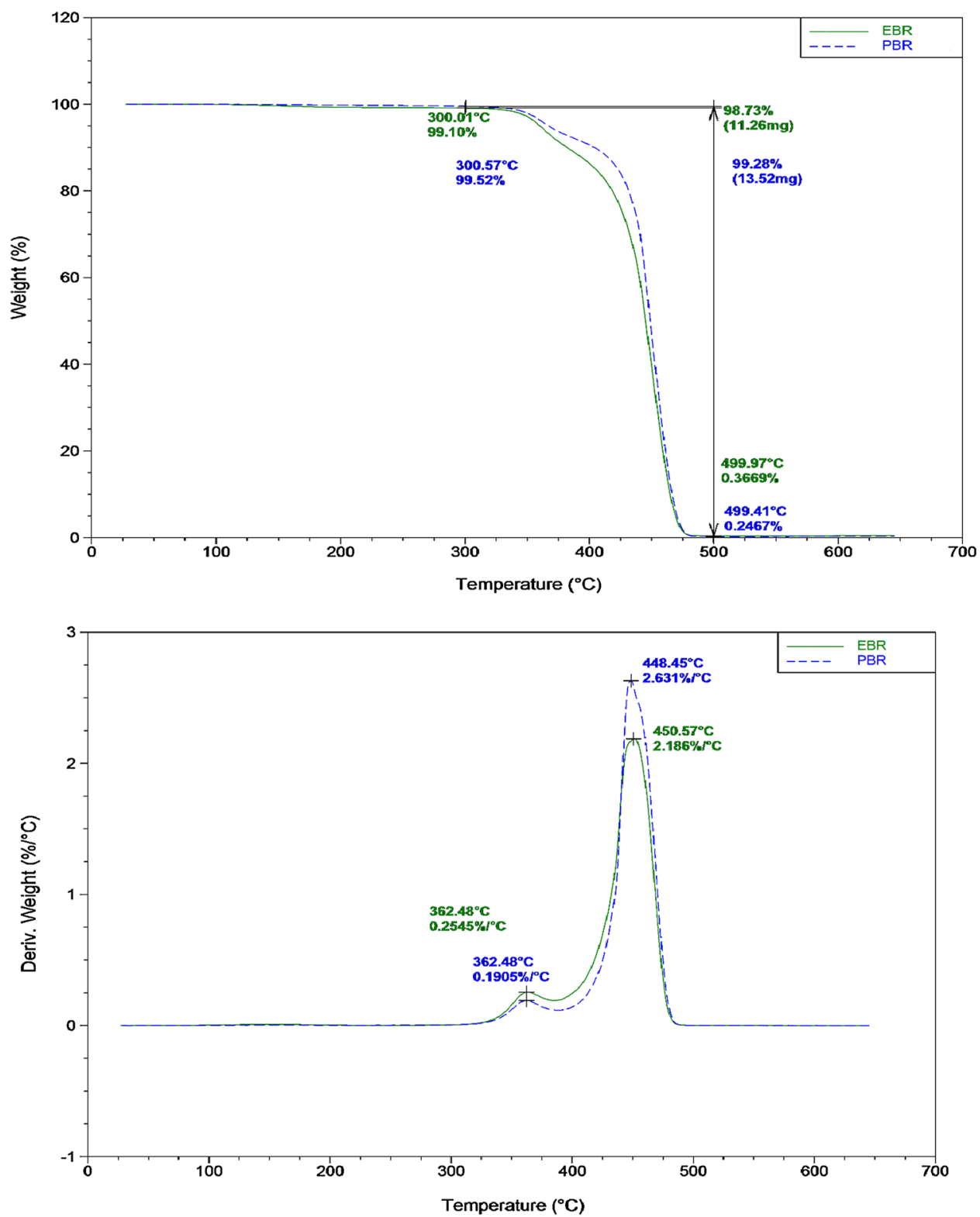

Table 2 Mechanical properties of SBR/BR-silica composites containing various coupling agent

\begin{tabular}{lllllll}
\hline Properties & Sample A & Sample B & Sample C & Sample D & Sample E & Sample F \\
\hline Tensile strength, MPa & 5.40 & 10.55 & 8.13 & 6.29 & 7.51 & 4.75 \\
Hardness, shore A & 64 & 66 & 58 & 62 & 63 & 62 \\
Elongation at break, \% & 555 & 377 & 460 & 303 & 560 & 595 \\
$100 \%$ modulus, $\mathrm{MPa}$ & 1.60 & 3.92 & 2.80 & 2.71 & 2.45 & 1.52 \\
$300 \%$ modulus, $\mathrm{MPa}$ & 3.28 & 6.09 & 5.90 & 3.17 & 4.31 & 3.04 \\
$V_{\mathrm{r}}$ & 0.182 & 0.281 & 0.186 & 0.185 & 0.221 & 0.156 \\
Crosslink density $\times 10^{-4}$ & 0.80 & 2.55 & 0.85 & 0.83 & 1.32 & 0.54 \\
\hline
\end{tabular}

Sample A composite sample without any compatibilizer, Sample B composite sample using TESPT as a coupling agent, Sample $C$ composite sample using APS as a coupling agent, Sample D composite sample using EBR10 as a coupling agent, Sample E composite sample using EBR30 as a coupling agent, and Sample $F$ composite sample using EBR50 as a coupling agent 
Scheme 2 Proposed coupling reaction in the presence of TESPT<smiles>CCO[Si](C)(OCC)O[SiH](OC)O[Si]12O[SiH](O[SiH](O)OC)O[Si](C)(OC)O[Si](C)(O[Si](C)(OCC)O1)O[Si](C)(O[SiH](C)OC)O2</smiles>

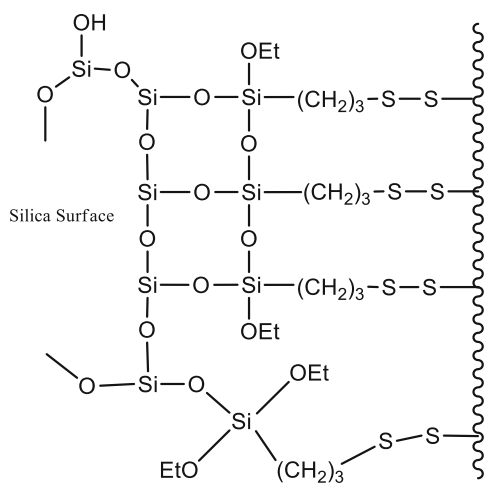
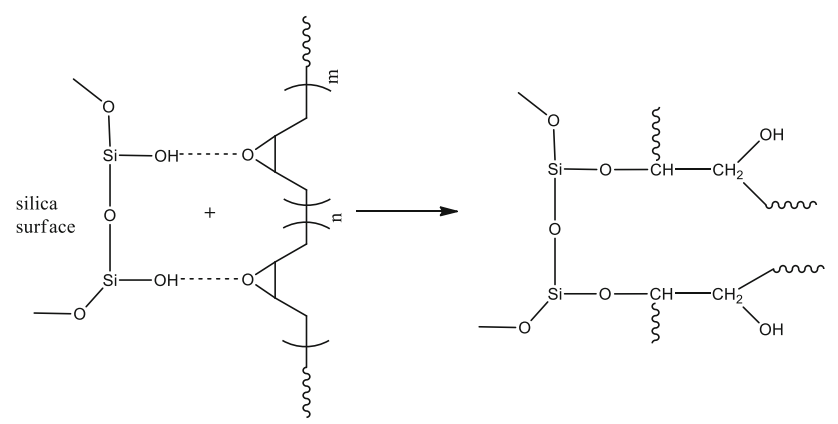

Scheme 3 Proposed coupling reaction in the presence of EBR

filler particles were uniformly dispersed in Sample B, Sample K, and Sample L, whereas an agglomeration of silica particles was observed in Sample A (without any compatibilizer). The observed SEM images clearly reflect that the utilization of EBR along with TESPT improved the silica filler dispersion by interaction between free $-\mathrm{OH}$ groups of silica surface with oxirane ring of EBR30 rubber chain to form strong interaction.

\section{Dynamic mechanical properties}

It has been reported that wet skidding resistance and rolling resistance of tires are generally determined by the $\tan \delta$ value at temperatures of -20 to 0 and 50 to $70{ }^{\circ} \mathrm{C}$, respectively [32]. Higher $\tan \delta$ value at temperatures of -20 to $0{ }^{\circ} \mathrm{C}$ corresponds to improved wet skidding resistance, whereas lower $\tan \delta$ value at temperatures of $50-70{ }^{\circ} \mathrm{C}$ relates to low rolling resistance. Therefore, to investigate the influence of employed compatibilizers EBR, TESPT, and APS in BR/SBR rubber matrix, the tan $\delta$ (loss factor) of various samples were compared (Fig. 11). It was observed that the $\tan \delta$ at lower temperature $\left(-20\right.$ to $\left.0{ }^{\circ} \mathrm{C}\right)$ was higher for Sample B followed by Sample L as compared to those observed for the Sample A (without any compatibilizer). Therefore, both the Sample B and Sample L will show better wet skid resistance as compared to other Sample A, Sample K and Sample M. Moreover, the $\tan \delta$ at
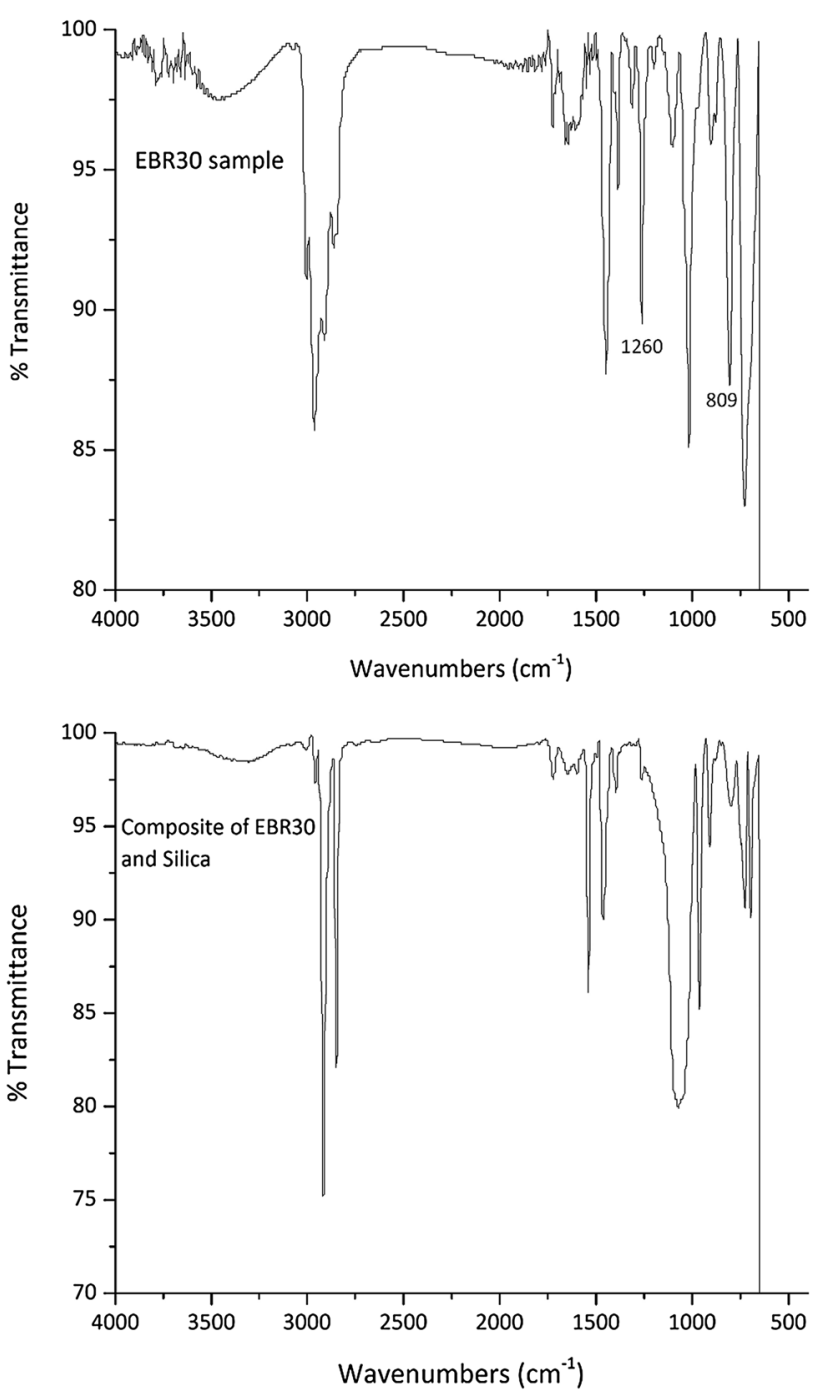

Fig. 5 FTIR spectra of EBR30 and composite of EBR30 and silica samples

higher temperatures $\left(50-70{ }^{\circ} \mathrm{C}\right)$ was lower for the Sample B followed by Sample L as compared to those observed for Sample A (without any compatibilizer). Therefore, it can be concluded that the Sample B and Sample L would 


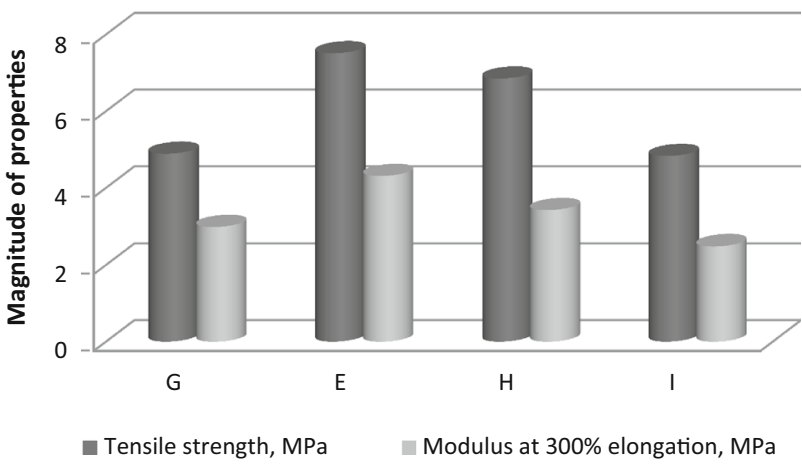

Fig. 6 Effect of variation of loading of EBR30 loading level on the tensile strength and modulus of the composite samples

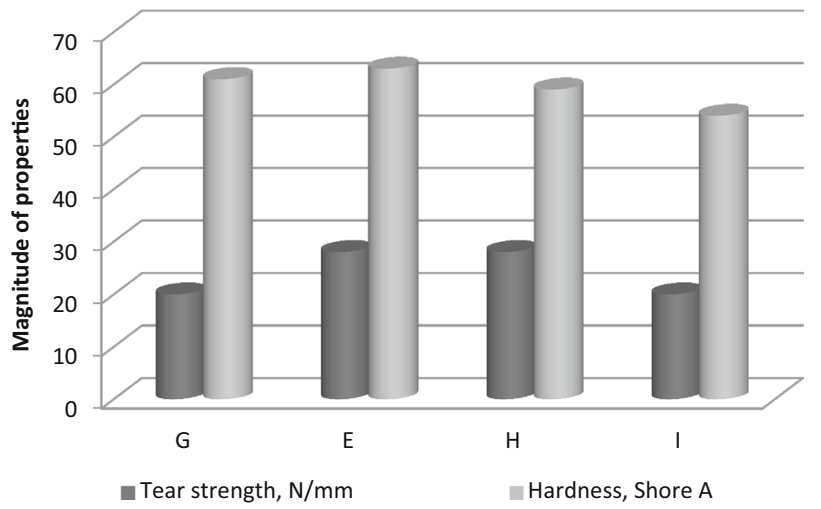

Fig. 7 Effect of variation of loading of EBR30 loading level on the tear strength and hardness of the composite samples. Sample $G$ composite sample using EBR30 loading as 8\% of silica content, Sample E composite sample using EBR30 loading as $12 \%$ of silica content, Sample H composite sample using EBR30 loading as $25 \%$ of silica content, and Sample I composite sample using EBR30 loading as $50 \%$ of silica content

show better rolling resistance and wet skid resistance than other Sample A, Sample K, and Sample M. Important to mention here that the Sample L (60 phr EBR30 and 40 phr TESPT silane as a compatibilizer) and Sample B (only TESPT silane as a compatibilizer) have shown comparable dynamic properties which further confirms potential effectiveness of EBR30 as a compatibilizer in green-tire composites.

\section{Effect of EBR on viscoelastic properties of the composites}

The viscoelastic behaviors of various composite samples as a function of strain percentage at $60{ }^{\circ} \mathrm{C}$ were also investigated for some of the samples (Fig. 12). The typical features of the Payne effect, i.e., a decrease in the storage modulus with increasing strain, can be seen for all the studied composite samples. The Payne effect amplitude, was calculated as a decrease in the magnitude of the nonlinear effect was observed to follow the trend as Sample $\mathrm{E}<$ Sample $\mathrm{L}=$ Sample $\mathrm{B}<$ Sample $\mathrm{C}<$ Sample $\mathrm{M}$. The efficient silanization of EBR30 sample can be seen from the observed lower values of the composite Sample E and Sample L, which reflects a better rubber-filler interaction in the composite samples.

Interestingly, unlike the physico-mechanical properties, the dynamic mechanical properties of EBR-containing composite samples were comparable with the corresponding composite sample containing the conventional silane like TESPT. Moreover, for the composite Sample M, ineffective silanization was observed which reduces rubber-filler interaction as explained in Scheme 4.

In addition, the Payne effect amplitude v/s $V_{\mathrm{r}}$ was also plotted (Fig. 13), where values followed a reverse trend in comparison to the trend observed for $V_{\mathrm{r}}$. The higher $V_{\mathrm{r}}$ values can be observed in Sample B and Sample L due to additional crosslinking which caused by the presence of conventional silane TESPT in the composite sample.
Table 3 Physico-mechanical properties of different SBR/BRsilica composites sample containing combination various loading of TESPT and EBR30 compatibilizers

\begin{tabular}{lllllll}
\hline Properties & Sample B & Sample C & Sample J & Sample K & Sample L & Sample M \\
\hline Hardness, shore A & 66 & 58 & 64 & 66 & 74 & 61 \\
Tensile strength, MPa & 10.55 & 8.13 & 9.54 & 9.33 & 9.85 & 6.73 \\
Elongation at break, \% & 277 & 460 & 340 & 309 & 386 & 425 \\
$100 \%$ modulus, MPa & 3.92 & 2.80 & 2.81 & 3.24 & 2.94 & 2.38 \\
$300 \%$ modulus, MPa & 6.09 & 5.90 & 8.56 & 8.95 & 7.73 & 4.95 \\
Tear strength, N/mm & 29 & 35 & 28 & 28 & 29 & 28 \\
Abrasion loss, g/40 m & 0.168 & 0.225 & 0.233 & 0.218 & 0.199 & 0.206 \\
Cut and chip, g/10 min & 2.83 & 3.28 & 2.46 & 2.82 & 2.83 & 3.21 \\
$V_{\mathrm{r}}$ & 0.311 & 0.209 & 0.231 & 0.265 & 0.243 & 0.183 \\
\hline
\end{tabular}

Sample B composite sample using TESPT as a coupling agent, Sample $C$ Composite sample using APS as a coupling agent, Sample J composite sample using combination of EBR30: TESPT (40:60 ratio), Sample K composite sample using combination of EBR30:TESPT (50:50 ratio), Sample L composite sample using combination of EBR30:TESPT (60:40 ratio), and Sample $M$ composite sample using combination of EBR30:APS (60:40 ratio) 
Scheme 4 Proposed reaction between the amino-group of APS and oxirane ring of EBR30

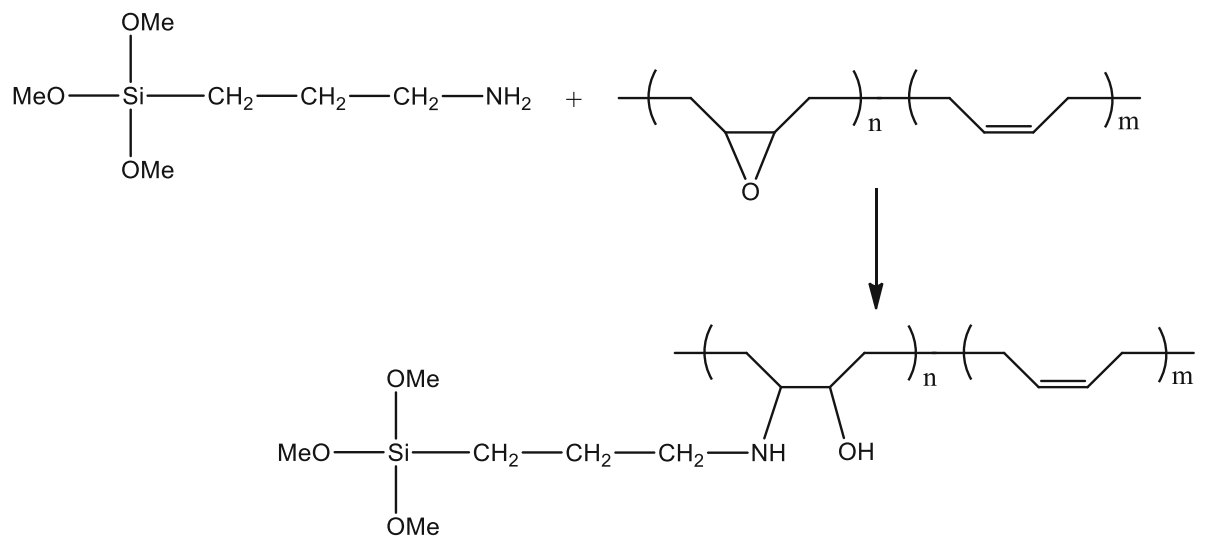

Table 4 Cure characteristics of various samples

Table 5 Bound rubber content

\begin{tabular}{lccccc}
\hline & Sample A & Sample B & Sample K & Sample L & Sample M \\
\hline$M_{\mathrm{L}}(\mathrm{d} N-M)$ & 4.9 & 3.3 & 4.2 & 4.5 & 5.6 \\
$M_{\mathrm{H}}(\mathrm{d} N-M)$ & 25.77 & 31.48 & 28.89 & 30.08 & 21.59 \\
$t_{\mathrm{s} 2}(\min )$ & 4.07 & 4.04 & 4.07 & 3.76 & 1.11 \\
$t_{90}(\min )$ & 10.01 & 17.39 & 15.33 & 14.34 & 5.74 \\
$\Delta$ Torque $\left(M_{\mathrm{H}}-M_{\mathrm{L}}\right)(\mathrm{d} N-M)$ & 20.87 & 28.15 & 24.65 & 25.43 & 15.98 \\
\hline
\end{tabular}

\begin{tabular}{llllll}
\hline & Sample A & Sample B & Sample K & Sample L & Sample M \\
\hline Bound rubber content $(\%)$ & 46 & 79 & 69 & 74 & 51 \\
\hline
\end{tabular}

Sample A composite sample without any compatibilizer, Sample B composite sample using TESPT as a coupling agent, Sample K composite sample using combination of EBR30:TESPT (50:50 ratio), Sample L composite sample using combination of EBR30:TESPT (60:40 ratio), and Sample $M$ composite sample using combination of EBR30:APS (60:40 ratio)

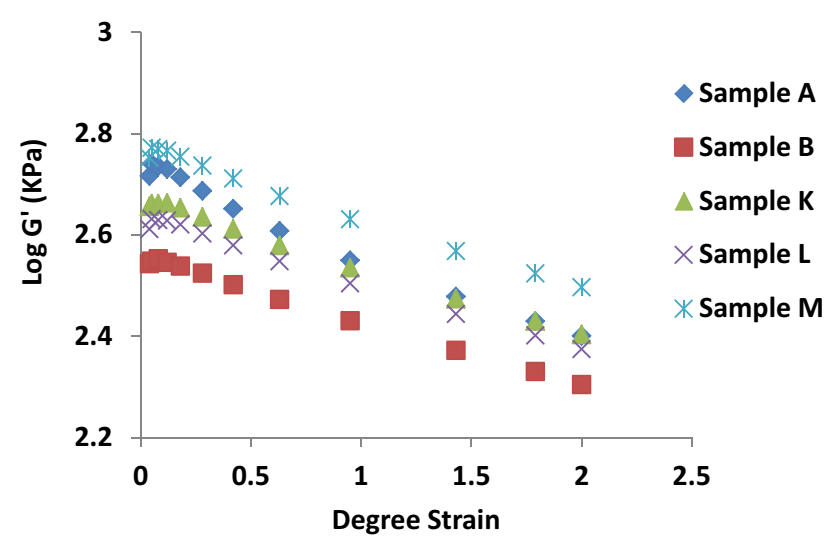

Fig. 8 Log storage modulus of uncured samples as a function of degree strain

\section{Conclusions}

In the present work, epoxidized polybutadiene rubber (EBR) was synthesized, characterized and used as a compatibilizer in SBR/BR-silica composite blend. With increasing epoxidation level, the compatibilization effect

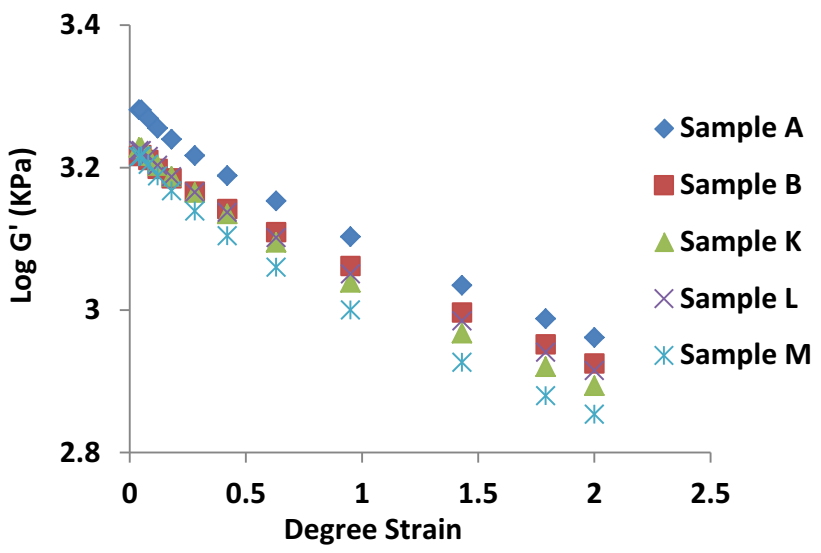

Fig. 9 Log storage modulus of cured samples as a function of degree strain. Sample A composite sample without any compatibilizer; Sample $B$ composite sample using TESPT as a coupling agent; Sample $K$ composite sample using combination of EBR30:TESPT (50:50 ratio), Sample $L$ composite sample using combination of EBR30:TESPT (60:40 ratio), and Sample $M$ composite sample using combination of EBR30:APS (60:40 ratio)

increased till $30 \mathrm{~mol} \%$ epoxidation (EBR30) and then decreased at higher epoxidation level $(50 \mathrm{~mol} \%)$. In addition, $12 \%$ loading was found as an optimum loading of 
Fig. 10 SEM images of various samples. Sample A composite sample without any compatibilizer; Sample B composite sample using TESPT as a coupling agent; Sample $K$ composite sample using combination of EBR30:TESPT (50:50 ratio), and Sample $L$ composite sample using combination of EBR30:TESPT (60:40 ratio)
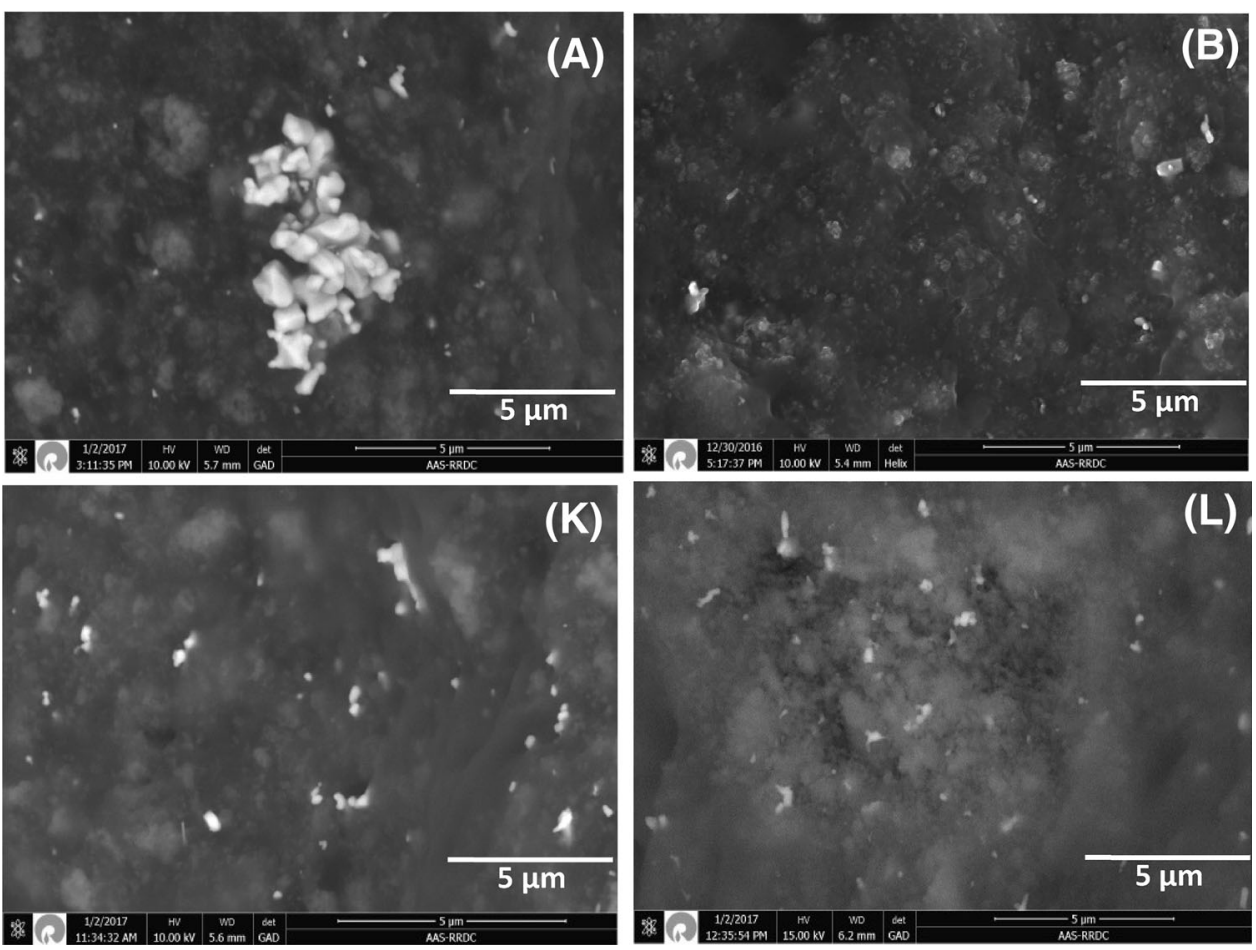

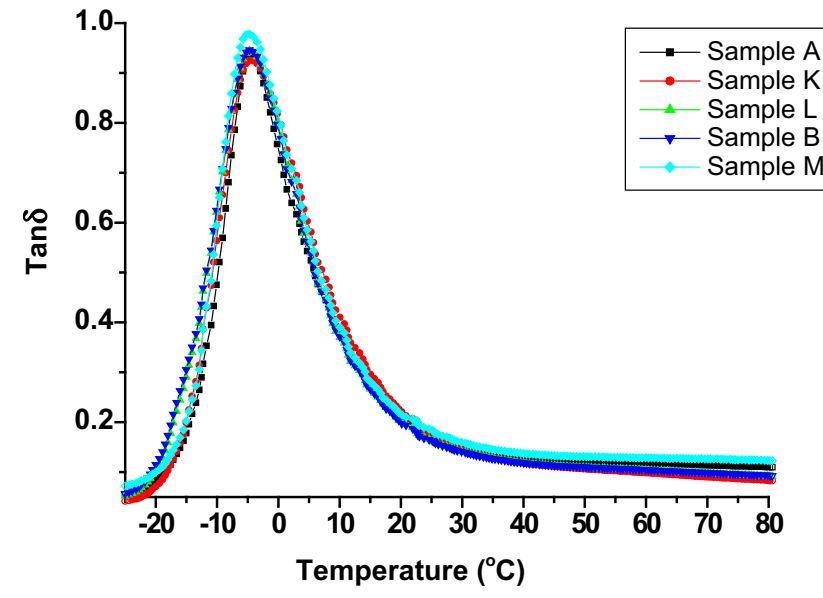

Fig. 11 Temperature dependence of $\tan \delta$ values. Sample A composite sample without any compatibilizer; Sample $B$ composite sample using TESPT as a coupling agent; Sample $K$ composite sample using combination of EBR30:TESPT (50:50 ratio), Sample L composite sample using combination of EBR30:TESPT (60:40 ratio), and Sample $M$ composite sample using combination of EBR30:APS (60:40 ratio)

EBR30 in composite sample. It was observed that although EBR can function as an effective compatibilizer, however, all the physico-mechanical properties obtained with commercial silane-coupling agent, TESPT was better than those of EBR-containing composite samples. The physicomechanical properties of the composite sample containing combination of TESPT:EBR (40:60-60:40) were

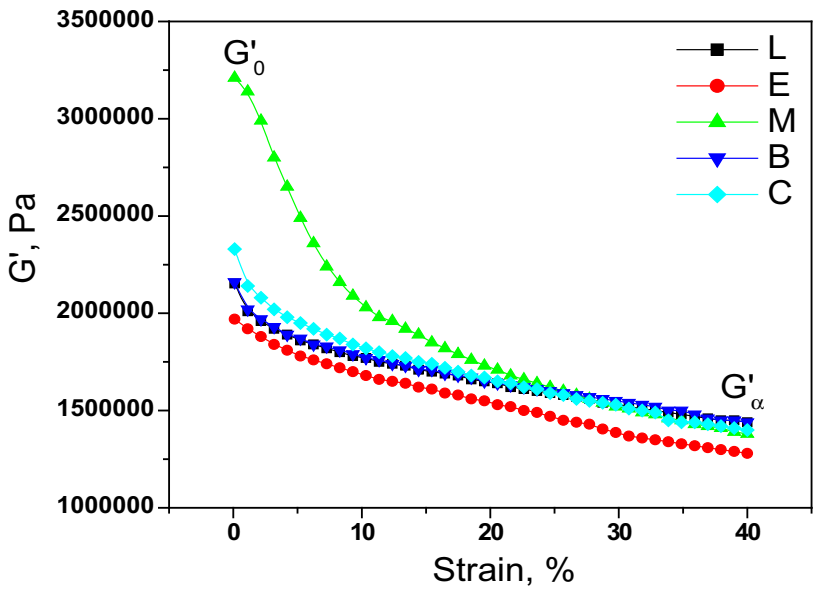

Fig. 12 Plot of storage modulus versus percentage strain

comparable with those of TESPT containing composite samples. On the other hand, the dynamic mechanical properties obtained while using the composite sample containing combination of TESPT:EBR (40:60) were comparable to the corresponding composite sample containing TESPT as a compatibilizer. The rheological, bound rubber content, Payne effect, and SEM results indicated the good compatibility between polar-EBR matrix and polar silica nanoparticles. The dynamic properties of the samples measured at low and high temperatures improved both good rolling as well as wet skid resistance. Finally, it can be concluded that in the Green-tire composite, $40-60 \%$ of the expensive conventional silanes can be replaced by 


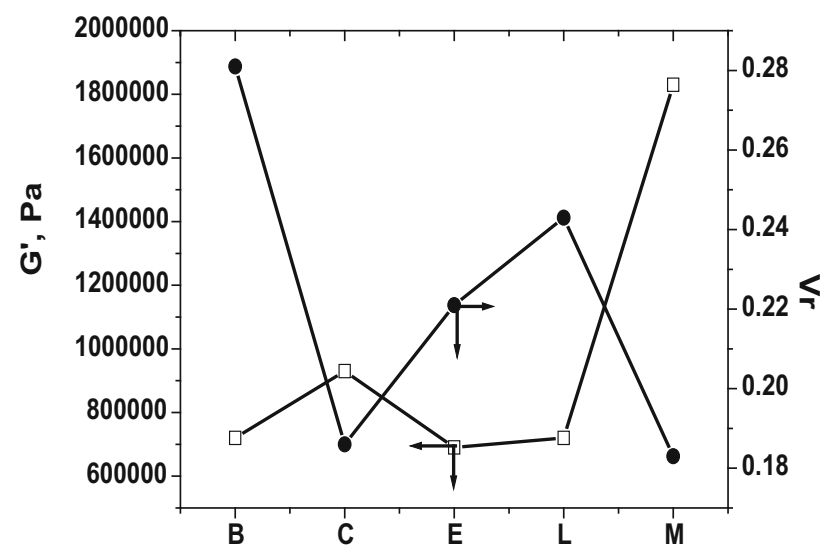

Fig. 13 Plot of Payne effect amplitude versus volume fraction of rubber. Sample B composite sample using TESPT as a coupling agent, Sample $C$ composite sample using APS as a coupling agent, Sample E composite sample using EBR30 as a compatibilizer, Sample $L$ composite sample using combination of EBR30:TESPT (60:40 ratio), and Sample $M$ composite sample using EBR30:APS (60:40 ratio) as a compatibilizer

EBR30 sample without sacrificing the properties and reducing the advantages associated with silanes.

Acknowledgements The authors are thankful to Ms. Anuradha Devi, Mr. H. Makwana, Mr. S. Agrawal, Mr. C. S. Shah and Mr. A. Chavda for their kind assistance during this research work. The authors are thankful to Reliance Industries Ltd. for the consent of publishing the work.

Open Access This article is distributed under the terms of the Creative Commons Attribution 4.0 International License (http://crea tivecommons.org/licenses/by/4.0/), which permits unrestricted use, distribution, and reproduction in any medium, provided you give appropriate credit to the original author(s) and the source, provide a link to the Creative Commons license, and indicate if changes were made.

Publisher's Note Springer Nature remains neutral with regard to jurisdictional claims in published maps and institutional affiliations.

\section{References}

1. Noordermeer JWM (1998) Recent developments in rubber processing leading to new applications such as the "Green Tire". Macromol Symp 127:131-139

2. Job KA (2014) Trends in green tire manufacturing. Rubber World Magazine March 1

3. Weiwei L, Xinxin Z, Thomas PR, Kuo-chih H, Xiaoping Y, He Q, Wencai W, Fanzhu L, Runguo W, Liqun Z (2016) High performance bio-based elastomers: energy efficient and sustainable materials for tires. J Mater Chem A 4:13058-13062

4. John TB (2002) Fillers for balancing passenger tire tread properties. Rubber Chem Technol 75:527-547

5. Das A, De-Yi Wang, Stockelhuber KW, Jurk R, Fritzsche J, Klueppel M, Heinrich G (2011) Rubber-clay nanocomposites: some recent results. Adv Polym Sci 239:85-166

6. Zhang Y, Ge S, Tang B, Koga T, Rafailovich MH, Sokolov JC, Peiffer DG, Li Z, Dias AJ, McElrath KO et al (2001) Effect of carbon black and silica fillers in elastomer blends. Macromolecules 34:7056-7065

7. Niedermeier W (2005) Off-the-road tires: challenges for carbon black and silica. Rubber World 232:24-30

8. Futamura S, Kuo-Chih H (2010) Important roles of polymers and fillers for tire performance characteristics of tread compounds. Rubber World 242:17-19

9. Flanigan CM; Beyer L, Klekamp D, Rohweder D, Stuck B, Terrill ER (2011) Comparative study of silica, carbon black and novel fillers in tread compounds. In: Technical Meeting- American Chemical Society, Rubber Division, 180th \& Advanced Materials in Health Care, Cleveland, $\mathrm{OH}$, United States, vol 1, pp 504-535

10. Dong-Woo Kim, Keun-Wan Park, Chowdhury SR, Gue-Hyun Kim (2006) Effect of compatibilizer and silane coupling agent on physical properties of ethylene vinyl acetate copolymer/ethylene1-butene copolymer/clay nanocomposite foams. J Appl Polym Sci 102:3259-3265

11. Tang Z, Huang J, Wu X, Guo B, Zhang L, Liu F (2015) Interface engineering toward promoting silanization by ionic liquid for high-performance rubber/silica composites. Ind Eng Chem Res 54:10747-10756

12. Dohi H, Horiuchi S (2007) Locating a silane coupling agent in silica-filled rubber composites by EFTEM. Langmuir 23:12344-12349

13. Shabbir S, Zulfiqar S, Al-Amri IS, Sarwar MI (2013) Enhancement of thermal stability, processability and morphology of polystyrene blends. Thermochim Acta 573:213-219

14. Seo G, Park SM, Ha K, Choi KT, Hong CK, Kaang S (2010) Effectively reinforcing roles of the networked silica prepared using 3,3'-bis(triethoxysilylpropyl)tetrasulfide in the physical properties of SBR compounds. J Mater Sci 45:1897-1903

15. Hattori T, Matsuura A, Hirayama M, Uesaka K (2014) Tire rubber composition and pneumatic tire. United States Patent 8846791

16. Martin PMC, Erik DS, Samuel JT (1995) Functionalization of polymers by metal-mediated processes. Chem Rev 95:381-398

17. Liezhong G, Richard PW, Anthony DF, Konstantin G (1999) Synthesis and characterization of high molecular weight carboxylated polybutadiene. J Polym Sci Part A Polym Chem 37:3129-3138

18. Abdelaziz NA, Howard A (1996) Catalytic oxidation of polybutadienes based on a Wacker-Type reaction. Macromolecules 29:5072-5074

19. Danuta Z (1980) Polybutadiene modified by epoxidation. 1 . Effect of polybutadiene microstructure on the reactivity of double bonds. Polymer 21:514-520

20. Ying Z, Xin-Zhong C, Yong Z, Yin-Xi Z (2001) Preparation of epoxidized rubber using a reactive processing technique. I. Synthesis and characterization of epoxidized polybutadiene rubber. J Appl Polym Sci 81:2987-2992

21. Ostad-Movahed S, Ansarifar A, Song M (2009) Effects of different interphases on the mechanical properties of cured silanized silica-filled styrene-butadiene/polybutadiene rubber blends for use in passenger car tire treads. J Appl Polym Sci 113:1868-1878

22. Bortolotti M, Viola GT, Busetti S, Mistrali F (1996) Elastomeric composition useful for tyre treads. EP0763564A3

23. Kawasaki S (2009) Rubber composition for tire and pneumatic tire US20100206444

24. Sandstrom PH, Segatta TJ, Verthe JJA (1994) Sulfur cured rubber composition containing epoxidized natural rubber and silica filler. EP644235

25. Yagi N, Muraoka K (2005) Rubber composition for tire tread and pneumatic tire using the same. US7709560

26. Jacobi MM, Braum MV, Rocha TLAC, Schuster RH (2007) Lightly epoxidized polybutadiene with efficient interaction to precipitated silica. Kaut Gummi Kunstst 60:460-466 
27. Chih-Cheng P, Volker A (2005) A simple pathway toward quantitative modification of polybutadiene: a new approach to thermoreversible cross-linking rubber comprising supramolecular hydrogen-bonding networks. Macromolecules 38:5575-5580

28. Maiti M, Bhowmick AK (2006) Structure and properties of some novel fluoroelastomer/clay nanocomposites with special reference to their interaction. J Polym Sci Pol Phys 44:162-176

29. Ogah OA, Afiukwa NJ, Nduji AA (2014) Characterization and comparison of rheological properties of agro fiber filled highdensity polyethylene bio-composites. Open J Polym Chem 4:12-19
30. Leblanc JL (2000) Elastomer-filler interactions and the rheology of filled rubber compounds. J Appl Polym Sci 78:1541-1550

31. Fowkes FM (1967) Treatise on adhesion and adhesives. Patrick RL (ed) Marcel Dekker Inc

32. Zhao Z, Zhao X, Gong G, Zheng J, Liang T, Yin C, Zhang Q (2012) Influence of particle type and silane coupling agent on properties of particle-reinforced styrene-butadiene rubber. Polym Plast Technol Eng 51:268-272 